Orlando Lopes

Tiago Martins

Vitor Carvalho

Demétrio Matos

Filomena Soares

José Machado

DOI: $10.21278 /$ TOF.40408

ISSN 1333-1124

eISSN 1849-1391

\title{
ERGONOMICS AND USABILITY IN THE DEVELOPMENT OF A PORTABLE VIRTUAL GAMING DEVICE APPLIED IN PHYSIOTHERAPY
}

\begin{abstract}
Summary
The field of Physical Medicine and Motor Rehabilitation (PMMR) is a medical specialty that deals with the diagnosis and treatment of different pathologies that affect the human body mobility. This process is characterized by the repetition of movements becoming dull and off-putting for patients under treatment. Over the past few years, new strategies have been introduced, including virtual games, aiming at making this process more fun and motivating.

This paper presents the development of a mobile device for using virtual games that support the PMMR professional. It will be used both in the clinical setting as well as at home taking ergonomic and usability issues into account. We intend to offer professionals and their patients a chance to take advantage of the motivational potential of virtual interactive gaming enabling patients to undertake physiotherapy sessions in a more simple and convenient way.
\end{abstract}

Key words: $\quad$ physical and motor rehabilitation, virtual games, mobile device, industrial design.

\section{Introduction}

The field of Physical Medicine and Motor Rehabilitation (PMMR) is an independent medical specialty whose goal is to promote the physical and cognitive functionality in the activity (including behaviour), participation (including quality of life), and modification of personal and environmental factors. It is thus responsible for the prevention, diagnosis, treatment, and organization of rehabilitation of individuals with disabling medical conditions and co-morbidities in all age groups [1].

The technological evolution, to which we have long been witnesses over the past few years, allows us now to use virtual games in the field of interactive PMMR. Patients may also benefit from the fact that environments can be designed according to the specifics of their condition and progress during the physiotherapy intervention [2]. 
Nowadays, the devices that physiotherapists have at their disposal for the realization of virtual interactive games in their therapy sessions are far from the desired in terms of ergonomics, comfort, and usability. From an ergonomic point of view, products are considered as means through which human beings can perform certain tasks. These products then become part of the man-machine-environment system. When it comes to ergonomics, the goal is to optimize the well-being of mankind and promote the overall performance of a system or product, so that their performance is as comfortable and easy to people as possible $[3,4]$. This study demonstrates the usability and ergonomic issues taken into consideration in the development of a mobile device for PMMR which uses virtual games. This equipment was designed to integrate various components of a multimedia system that allows complementing traditional physiotherapy sessions with electronic games in order to motivate patients to perform their physiotherapeutic programmes with enthusiasm. This system is prepared to support sessions both in a clinical and in a domestic environment.

The paper is structured as follows: Section 2 presents the framework including the devices available on the market used to perform virtual interactive games in PMMR; Section 3 presents the development of different product concepts and the subsequent selection; Section 4 describes the usability tests, and finally, Section 5 gives the conclusion and considerations for further work.

\section{Framework}

Over the last years a series of devices have been developed with an interface that allows the common user to interact either with a computer, or with a panel, particularly with regard to the realization of games in a more natural way. As found earlier, the use of games for other than entertainment purposes is no longer new. Nowadays, games can be used also in PMMR.

Multiple devices employed to capture body movements to help with physical rehabilitation were used in this investigation. Such equipment was essential so that the professionals could verify the exercises and respond according to the movements, helping the patients to implement them. Some of the technologies that have been used are: RGB cameras with or without markers, haptic devices, accelerometers, optical sensors, and bio signals receivers [5].

It is possible to use one or more technologies to get information about the patient during treatment [5]. Optical sensors and bio signals receivers can precisely detect the movements and can capture information about the patient's muscle. However, the fact that these devices are connected to the patient's body can restrict the movements and cause discomfort. Such devices are also difficult to acquire and handle because of cost and complexity of use and configuration. Cameras and accelerometers can be more easily manipulated and are affordable for home treatment, allowing the sessions to be performed either in a clinical environment or at home [6].

A study by Burke [7] used an inexpensive camera with a game-based system to assist physiotherapy and stimulate the movement of the upper limbs of the body of patients who had suffered a cerebro-vascular accident (CVA). The coloured markers of the developed system (coloured gloves) for detecting the position are used as a game input device, as can be seen in Figure 1 . 
Ergonomics and Usability in the Development of a Portable Virtual Gaming Device Applied in Physiotherapy
O. Lopes, T. Martins, V. Carvalho

D. Matos, F. Soares, J. Machado

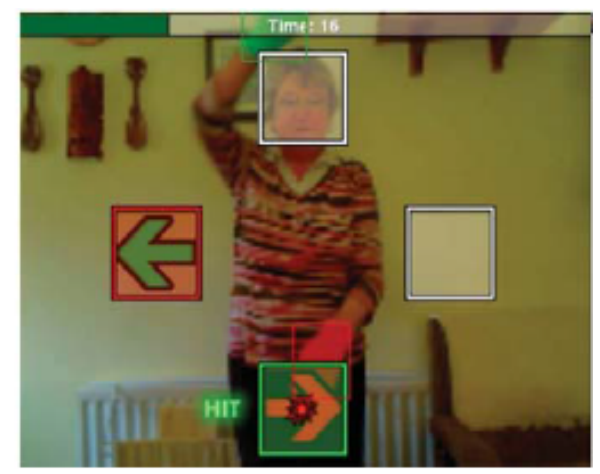

Fig. 1 Patient recovery session consisting of movements of upper limbs using virtual games and gloves as markers to detect position [7]

In his study, Evett performed motion capture using two cameras in serious games for stroke rehabilitation [8]: a RGB camera and a thermal camera to capture movement without the aid of markers (Figure 2) for a post-stroke movement recovery system. The use of the devices without markers allows the patient to perform movements freely without the impediment of equipment connected to the body, which can cause discomfort, hygiene restrictions, and difficulties related to the movement.
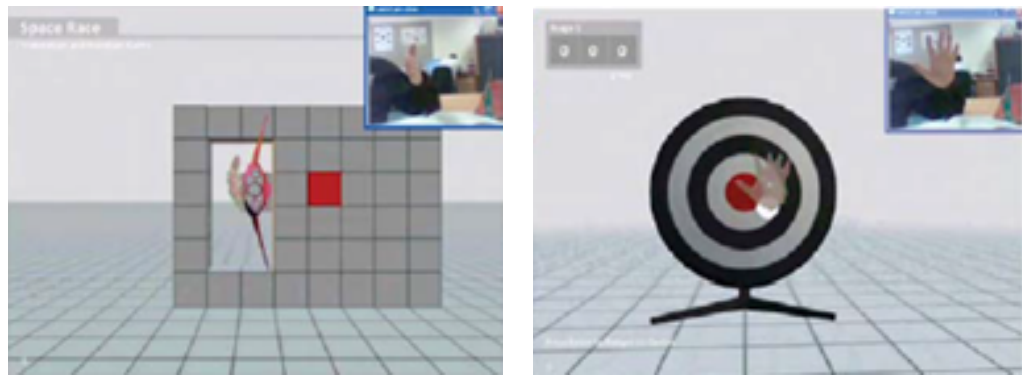

Fig. 2 Patient uses virtual games to help recover hand movements [8]

The optical sensors used by Schönauer [5] in a study on rehabilitation from chronic pain by means of a serious game using Multimodal entrance are composed of passive markers placed on the human body and responding to infrared transmitters that broadcast to the team. To detect the movement of a human being, such a device is positioned on different parts of the body in the frontal position.

The sets were used to respond to various data captured by the sensors for use in rehabilitation from chronic pain (Figure 3). The system's objective was to test the introduction of these devices as input devices for physical therapy games.

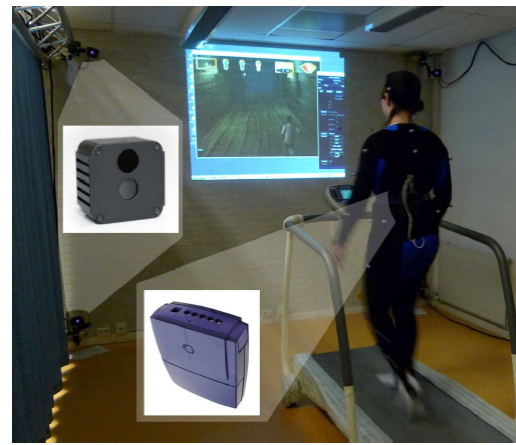

Fig. 3 Rehabilitation using virtual games and identifying movements with iotracker- camera and EAS-Mobi biological signals device [5] 
Currently on the market there are essentially three devices, namely Nintendo Wii, Sony PlayStation Move, and Microsoft Xbox 360 Kinect, which are consoles based on Virtual Reality (VR), with games that can be adapted to be used as physical rehabilitation games. None of these games was developed with the purpose of being used in PMMR.

Nintendo Wii (Figure 4), released in 2006, stands out from other consoles due to its wireless remote commands. The movements of the user are reflected in the projection, so that the virtual movements are similar to those performed in reality, as if the character "in" the game had reactions similar to those of the person who is using the device [9].

PlayStation Move (Figure 5) was released at the end of 2010. The motion controller PlayStation Move is composed of an advanced motion sensor - namely a ball - that changes colours dynamically and enables the camera to capture the position in space [9].

Kinect (Figure 6), released in 2010, was developed by Microsoft in partnership with Prime Sense and was a peripheral device sold by Microsoft for use on Xbox 360 (Figure 7), which allowed the user to interact naturally with the console through body gestures and voice commands. The user does not need physical controls, which allows the users with limited dexterity level to participate and benefit from this device [10].

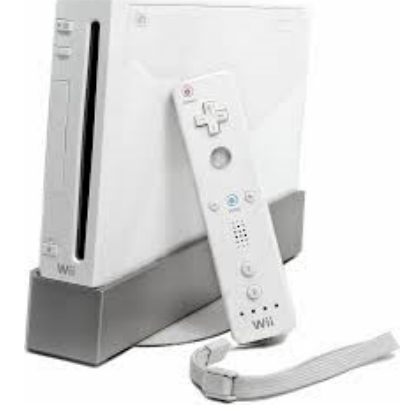

Fig. 4 Nintendo Wii and Wii Remote [19]

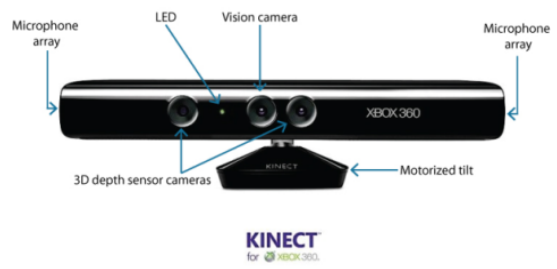

Fig. 6 Microsoft Kinect [21]

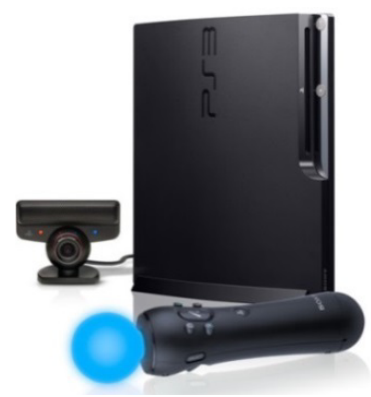

Fig. 5 Sony PayStation3 and Move [20]

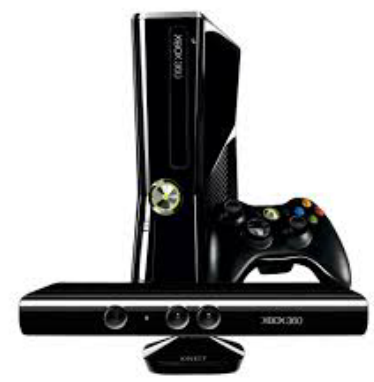

Fig. 7 Microsoft Xbox 360 and Kinect [21]

The video game industry has taken a turn with advances in the research in VR, namely, the development of high-tech devices available at affordable prices for the common user. Since these devices are produced and marketed on a large scale, the price for the end consumer becomes considerably lower facilitating their use in the development of new rehabilitation solutions.

Taking the potential of the three mentioned commercial devices in terms of interaction into account we can point out some considerations. The Nintendo Wii platform has some limitations for users with low manual dexterity and motor skills as it is necessary to press buttons at the command level to interact with the games. In contrast, Sony PlayStation Move has a function very similar to Nintendo Wii, but it is more accurate in terms of movements and detection; it should be noted that in this case it is no longer necessary to press any button 
to interact with the game, only a physical device is required. Thus, Microsoft Kinect proved to be the most innovative device since it does not need any physical command to interact with the games; it is only necessary to connect it to a computer or game console (for example: Xbox 360) and take the limit distance for positioning it relatively to the user into consideration, so it performs properly. The interaction is based entirely on the acquisition of image data and infrared sensing of the movements of the player [11].

However, all of these commercially available devices need to be connected to other equipment, making the assembly/disassembly task harder for the therapist. Moreover, according to the surveyed physiotherapists, the number of cables needed for connexion and the difficulties in transportation of all this equipment lead to the fact that this strategy is not used in PMMR.

Nowadays, technology plays an increasingly important role in health care. The increasing complexity of the medical technology forces health professionals to consider usability as an important criterion when selecting a therapeutic strategy. In this light, there is a growing awareness both within the medical technology industry community, and among the representatives of the medical profession that medical equipment should have greater usability to avoid errors and optimize the care provided [12].

\section{Product Development}

In the configuration of the industrial products process, the designer must optimize the functions of a product aimed at satisfying the needs of future users [13]. The clear identification of the needs of people is essential for success and product innovation in the market, and this is only possible while understanding the problems, desires, and environment in which people/users interact [14].

To identify the needs relating to this product and to rank them, we have performed a survey involving 38 physiotherapists in an age range between 20 and 46 years and working in 10 health units of the city of Braga, Portugal. After the analysis and processing of the data collected through the surveys, we can present the characteristics the respondents consider most important (Figure 8).

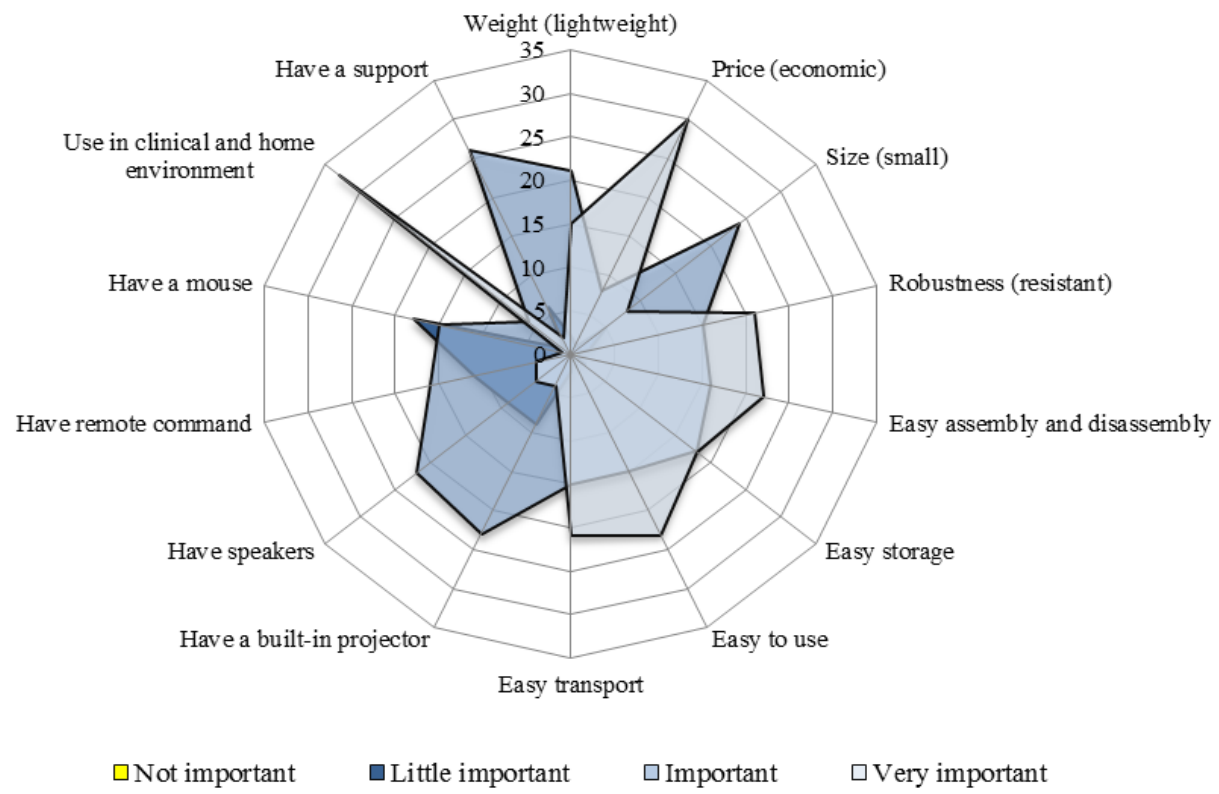

Fig. 8 Hierarchy of needs 
Designing consumer products requires a mixture of art and science, which can work harmoniously without diluting them. In fact, the more attention is paid to applying science and art towards the end users' safety and satisfaction, the more likely it is that the product will have a shaping influence on future design paradigms. Thus, a successful integration of ergonomics and industrial design will produce aesthetically pleasing and functionally superior products [15]. Based on this assumption, three different product concepts (A, B, C) were developed (Figure 9).
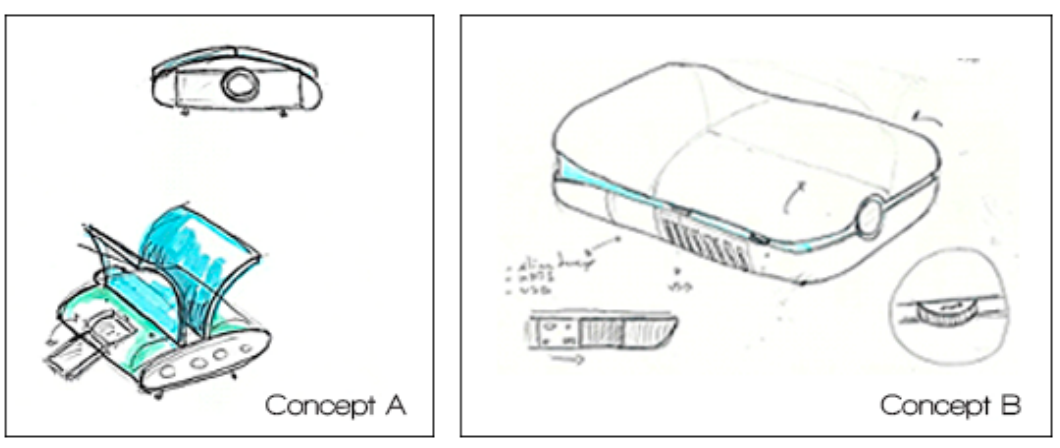

Fig. 9 Three different product concepts

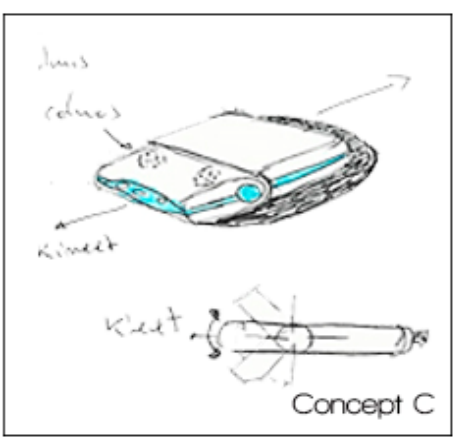

devin

The concept of system A is based on the integration of all devices considered important by the respondents, including a multimedia projector, a touchpad, speakers, and a PC. In general terms, the product architecture has an oval shape, whose top can be opened by lifting two flaps and thus the operator can have access to the touchpad and to the respective USB, HDMI inputs, and the device power source. The Kinect sensor is located on the back of the device and the projector is located in the front.

The concept of system B displays a very similar format to that of a bean and follows the same line of the previous concept action functionality. However, there was a concern to reduce the size of the product, so choosing product components to this end was considered. USB, HDMI and power supply are located on the side, and in order to access these components the operator has to open a door on the side. In this version the Kinect sensor will be placed on the back of the device as well as the speakers. The angle of the projector is adjusted through a device placed on the side, which will cause the projector to elevate.

The third and last concept is the re-structuring of the previous concept. Since this concept has proportions and sizes that were contrary to what was intended initially, a new innovative product resulted. In the concept $\mathrm{C}$, the device is composed of a central structure to which two parts are coupled. The first part is shaped like a cylinder in which the speakers and the Kinect sensor are installed, while the second part has a shape of a rectangular prism in which the projector, the mini PC and the touchpad are installed.

The device constituents were carefully considered, as compared to previous concepts, so that we can decrease the device size. This concept is characterized by the possibility of the Kinect adjustment by device rotation about an axis, allowing us a more efficient and personalized fit. This new format of the product mainly aimed at including features like portability and convenience as an added value that distinguishes it from all other existing products currently on the market.

To select the concept that is best to be developed, we referred to a graph by which we evaluated and compared the strengths and weaknesses of each of the concepts based on the needs of the respondents.

The results show that the best solution was concept $\mathrm{C}$ as shown in Figure 10. 


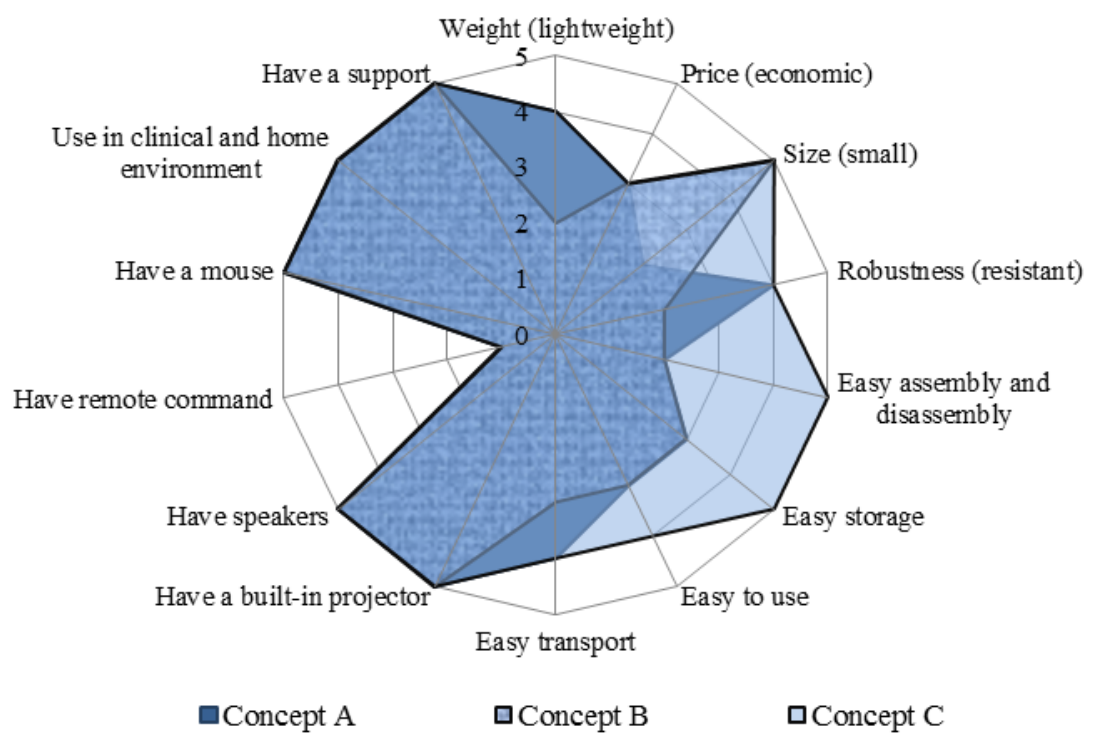

Fig. 10 Comparison between developed concepts

Once the concept had been selected, the first versions of the product were made to perform usability studies. Initially, we built a prototype that was not functional (Figure 11) in order to validate the proportions, the anthropometric dimensions applied to the product, and subsequently, to carry out usability testing as physical prototypes are considered almost indispensable tools for the development of products.

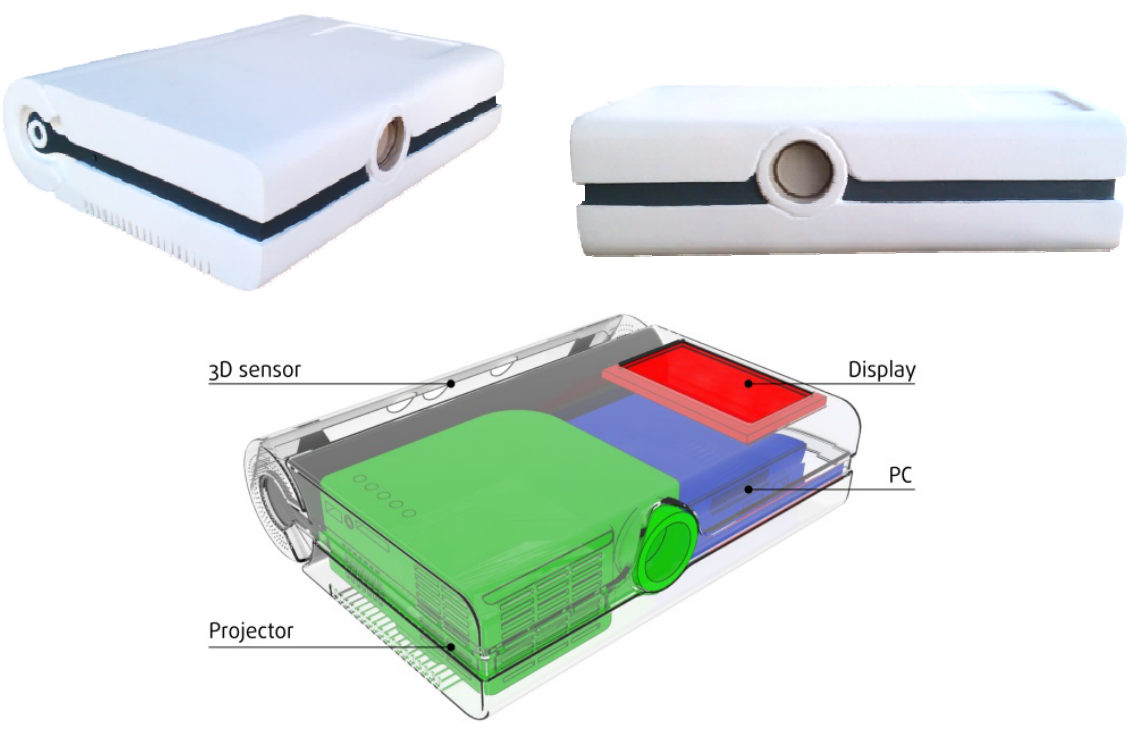

Fig. 11 Prototype device

The product has the following dimensions: $68 \mathrm{~mm}$ in height, $220 \mathrm{~mm}$ in width, and 288 $\mathrm{mm}$ in length (Figure 12). The cylinder diameter is designed taking the constraints of the hardware and the hand anatomy into account. The average measure of grip width of the hand was considered for comfortable handling [22]. 


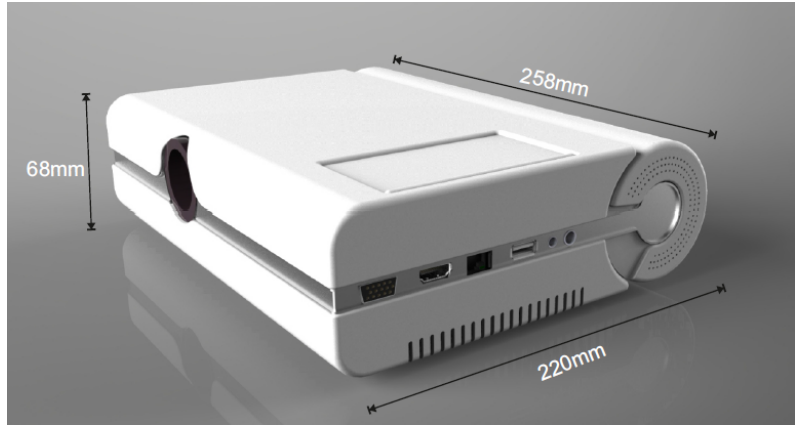

Fig. 12 Product dimensions

In Figure 13 we can see the adaptation of the product dimensions to the users and the elements. When the device is used (Figure 14), it must be at a 2 or $3 \mathrm{~m}$ distance from the patient. The patient is placed in front of the sensors (cylinder) so that the device can recognize him/her and then translate his/her movements in the game. At an early stage, the physiotherapist places the device to the left side so he/she can access the device's touchpad to adjust and select the exercises and after that can place it in a more relevant position.

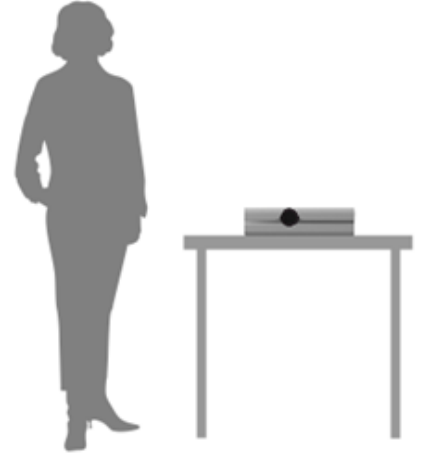

Fig. 13 Relationship between the product dimensions and users and various media

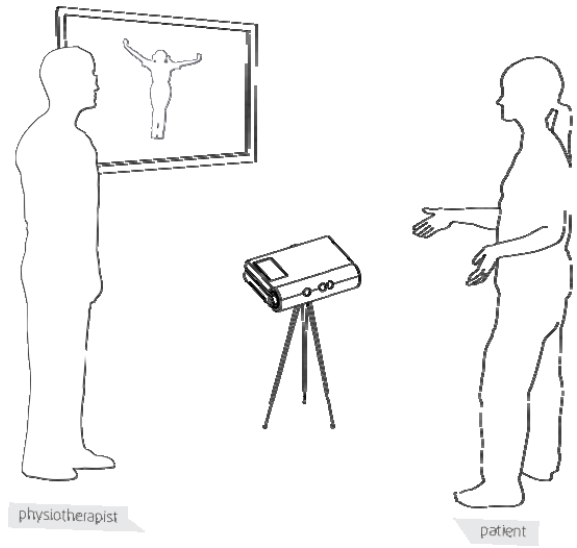

Fig. 14 Positions of the patient and therapist in respect to the device

\section{Usability Testing}

Usability basically means making sure that something works well: that an average person (or even below average), when it comes to ability and experience, can use a product for its intended purpose without getting hopelessly frustrated, whether it is a website, a fighter jet, or a revolving door [16].

A perspective more focused on the process of product development is provided by the Usability Professionals Association (UPA) as follows: "Usability is an approach to product development that incorporates directly user feedback throughout its development cycle in order to reduce costs, and create products and tools that meet the needs of users" [17]. In order to evaluate and validate the device's usability, some tests were performed under normal conditions of use, as part of physical therapy sessions, taking the issues of mobility into consideration. The tests focused on three aspects of usability: effectiveness, efficiency, and satisfaction. Also, the choice of users who were observed encompassed a wide variety of aspects including location and lifestyle among other requirements, in order to capture a whole 
range of various product perceptions [18]. From this perspective, we chose to apply the tests to a group consisting of five physiotherapists, two females and three males aged between 22 and 47 , to test the device. To evaluate the usability of direct observation, we used the Thinking Aloud method, considered by Nielsen to be the most valuable usability tests [18], in which users describe the actions taken, the decisions made, their opinions, and their feelings related to the use while interacting with the product and performing the tasks. In this case, the users had to fulfil the following tasks:

- Remove the device from the bag;

- Place the device in the proper operating position;

- Connect the device;

- Connect the device to a USB pen drive;

- Access the interface;

- Disconnect the device;

- Put the device back in the bag.

The study had no stipulated time limit for carrying out the tasks.

Figure 15 shows some of the usability tasks being performed by the users.
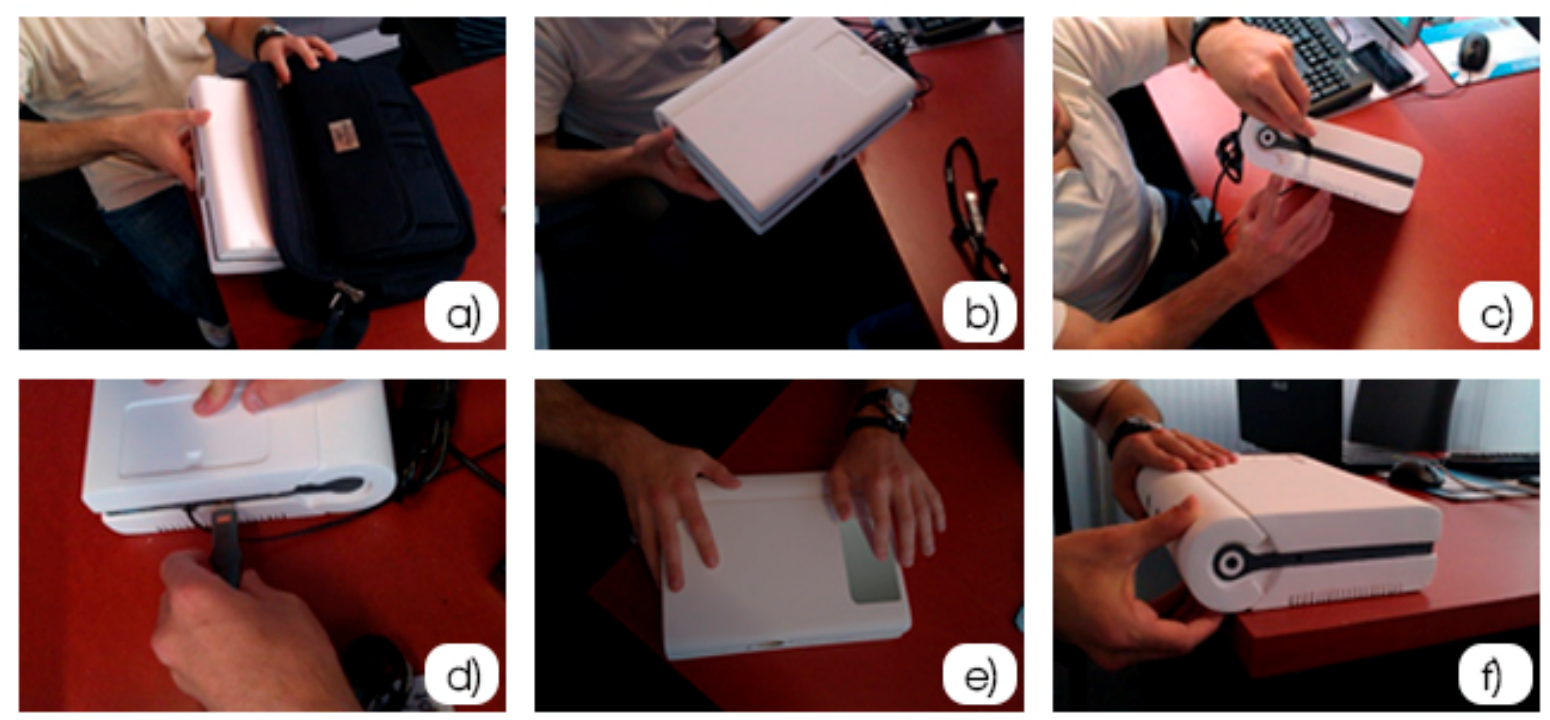

Fig. 15 Different phases of usability testing with users: a) Removing the device from the dag;

b) Free observation and manipulation of the device; c) Connecting the device; d) Connecting the USB pen;

e) Accessing the interface; f) Adjusting the position of the 3D sensor

Some observations are given below:

- Despite the fact that the users interacted with the device for the first time, all five of them completed all the tasks successfully and without needing help.

- The users were pleasantly surprised by the size of the device as they did not expect such a small product, which is quite easy to carry and pack (see Figure 12a).

- With respect to the operation of the device, the users considered the use to be quite simple and intuitive; they confirmed that the ON/OFF button and the device connecting inputs (USB pen, VGA cable, network cable, and speaker) were easy to find (see Figure 12d). 
- When it came to use the touchpad the first time, one of the users expressed some discomfort when opening the protection because he was left-handed. However, upon subsequent practice with his right hand, he decided that he could perform the task without exerting extra effort (Figure 12e).

- The five physiotherapists considered the device a quite interesting product in terms of aesthetics, with an intuitive and user-friendly operation and felt that it achieved the objective for which it was developed. They all declared that they would buy the product and that they would advise other professional colleagues to do the same, if available commercially.

- From an ergonomic point of view, all products, whether large or small, or simple or complex, are intended to satisfy certain human needs, and thus directly or indirectly come into contact with human beings. If proper functioning of these products is to be ensured at the level of interaction with users or consumers, they should have the following basic characteristics: technical quality, ergonomic quality, and aesthetics [3].

As can be seen in Figure 16a, the device used a PC, a monitor, a keyboard, a mouse, a projector, and Kinect (from left to right).

In Figure 16b, we show a product that we consider to be able to simplify and make the task of using virtual games as a part of PMMR more comfortable.
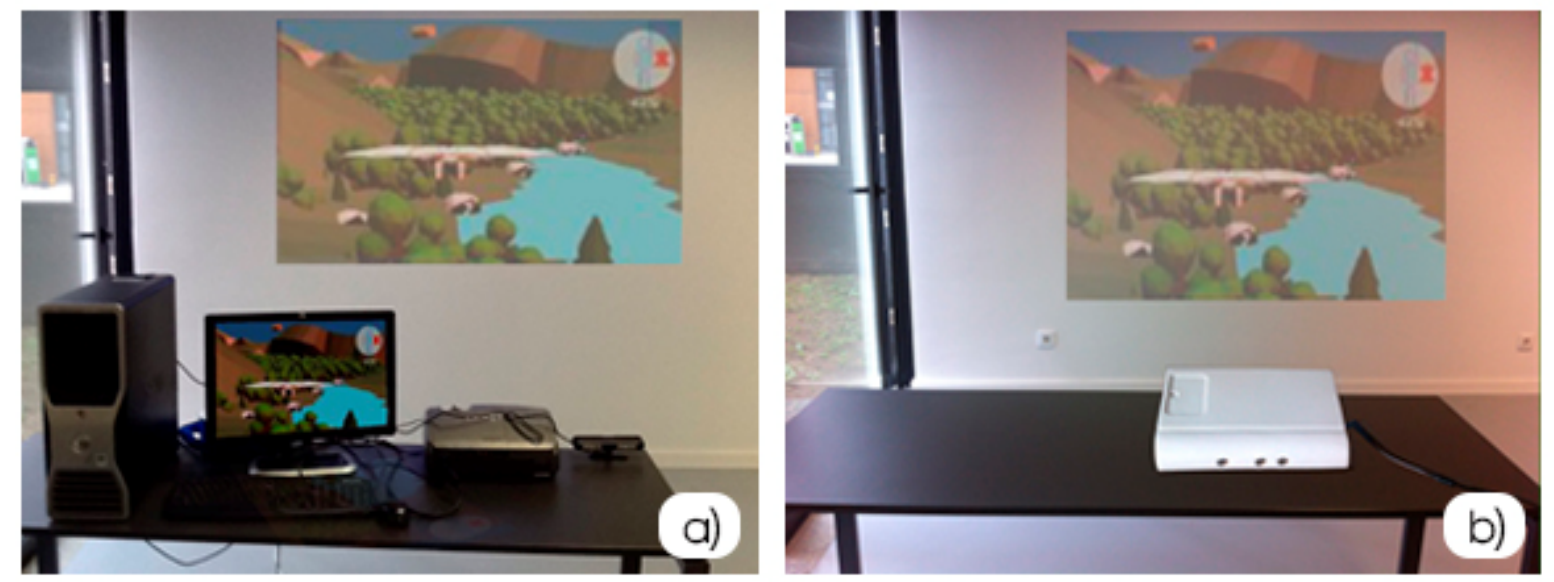

Fig. 16 Comparison of devices used in PMMR: a) Devices used currently; b) Proposed device

With the proposed solution multiple devices do not have to be used and connected any more, which can be impractical to transport and cause some confusion and complexity when the product is to be assembled and disassembled.

\section{Conclusion and Further Work}

In product development, where the factors relating to human movement and interaction with objects or products are relevant, it is essential that the issues of ergonomics and usability are taken into account and associated with the process of product design to allow for the achievement of more comfortable, safer, and more efficient and attractive solutions.

This paper presents a study undertaken with a goal to develop a portable device used by motor rehabilitation professionals to support the use of virtual games in physical medicine. The device is designed for use both in a clinical environment as well as in a domestic 
environment, and takes the ergonomic and usability issues into account. It is our belief that both the professionals and their patients can take advantage of the motivational use of virtual games being a part of physiotherapy sessions, transforming them in a more convenient way, which would lead to more efficient rehabilitation.

When developing this product, the main requirements considered were that the product was to be simple and comfortable for use by physiotherapists in order to facilitate the use of virtual games in PMMR. Consequently, as it is a single device, evaluated by the users to be quite intuitive to use, user-friendly and very easy to be transported and assembled and disassembled, we believe that the defined objectives have been attained.

Further work will consider the development of accessories for the integration with the presented device, such as a special holder (replacing the table), a transportation bag, and a smart phone or tablet remote control application.

\section{REFERENCES}

[1] C. Gutenbrunner, A. B. Ward, and M. A. Chamberlain, Livro Branco de Medicina Física e de Reabilitação na Europa. 2009.

[2] M. Ma, A. Oikonomou, and L. Jain, Serious Games and Edutainment Applications. Springer, 2011. DOI:10.1007/978-1-4471-2161-9

[3] R. Moraes, A. S.; Arezes, P. and Vasconcelos, "Articulating ergonomics and engineering design to develop healthy and safe work environments," Guimaraes, 2007.

[4] Feng, T., Zhang, Y., Jin, Y., Zhang, J. (2015). A compromise-negotiation framework based on Game theory for eliminating requirements inconsistency. Tehnički vjesnik, 22(5). pp. 1085-1092. DOI:10.17559/TV-20150731092521

[5] C. Schonauer, T. Pintaric, H. Kaufmann, S. Jansen-Kosterink, and M. Vollenbroek-Hutten, "Chronic pain rehabilitation with a serious game using multimodal input," 2011 Int. Conf. Virtual Rehabil. ICVR 2011, 2011.

[6] S. K. Chien-Yen Chang, Belinda Lange, Mi Zhang, "Towards Pervasive Physical Rehabilitation Using Microsoft Kinect," 6th Int. Conf. Pervasive Comput. Technol. Healthc., pp. 159-162, 2012. DOI:10.4108/icst.pervasivehealth.2012.248714

[7] J. W. Burke, M. D. J. McNeill, D. K. Charles, P. J. Morrow, J. H. Crosbie, and S. M. McDonough, "Optimising engagement for stroke rehabilitation using serious games," Vis. Comput., vol. 25, no. 12, pp. 1085-1099, Aug. 2009. DOI:10.1007/s00371-009-0387-4

[8] L. Evett, A. Burton, S. Battersby, D. Brown, N. Sherkat, G. Ford, H. Liu, and P. Standen, "Dual camera motion capture for serious games in stroke rehabilitation," in 2011 IEEE 1st International Conference on Serious Games and Applications for Health (SeGAH), 2011, pp. 1-4. DOI:10.1109/segah.2011.6165460

[9] A. Corrêa, C. Monteiro, T. da Silva, C. de Lima-Alvarez, I. Fichemann, E. Tudella, and R. Lopes, "Realidade Virtual e Jogos Eletrónicos: uma proposta para deficientes," in Realidade Virtual na Paralisia Cerebral, São Paulo: Plêiade, 2011, p. 222.

[10] T. A. Togores, "Vitruvius - Um Reconhecedor de Gestos para o Kinect —," Universidade de São Paulo, 2011.

[11] O. Lopes, T. Martins, V. Carvalho, and D. Matos, "Design and development of a portable projection and natural interface device for virtual games applied to physiotherapy," ICNAAM. 12th Int. Conf. Numer. Anal. Appl. Math., pp. 3-6, 2014.

[12] E. Liljegren, "Usability in a medical technology context assessment of methods for usability evaluation of medical equipment," Int. J. Ind. Ergon., vol. 36, no. 4, pp. 345-352, Apr. 2006. DOI:10.1016/j.ergon.2005.10.004

[13] I. Iida, Ergonomia: projeto e produção, $2^{\circ}$ ed. São Paulo: Edgard Blücher, 2005.

[14] K. T. Ulrich and S. D. Eppinger, Product Design and Development., $4^{\circ}$ ed. New York: Mc Graw Hill, 2008.

[15] R. Lin and J. G. Kreifeldt, "Ergonomics in wearable computer design," Int. J. Ind. Ergon., vol. 27, no. 4, pp. 259-269, Apr. 2001. DOI:10.1016/S0169-8141(00)00055-X 
[16] S. KRUG, Don't make me think! A common sense approach to Web usability, 2nd ed. Indianapolis: New Riders Press, 2005.

[17] U. P. Association, "What is Usability?," 2015. [Online]. Available: http://www.usabilityprofessionals.org/usability_resources/about_usability/definitions_of_usability.html. [Accessed: 28-Mar-2015].

[18] N. Jacob, Usability engineering. San Diego: Academic Press, 1993.

[19] Nintendo, “Nintendo Wii,” 2015. [Online]. Available: http://www.nintendo.pt/Wii/Acessorios/Acessoacute-rios-626430.html. [Accessed: 23-Feb-2015].

[20] Sony, "PlayStation Move," 2015. [Online]. Available: http://pt.playstation.com/psmove/. [Accessed: 25Feb-2015].

[21] Microsoft, "Xbox 360 Kinect," 2015. [Online]. Available: http://www.xbox.com/ptPT/Xbox360/Accessories/kinect/Home. [Accessed: 24-Feb-2015].

[22] H, Dreyfuss, The measure of human factors in design. United States: 1966.

Submitted: $\quad 08.7 .2015$

Accepted: $\quad 20.4 .2016$
Tiago Martins

Filomena Soares

tiagorsmartins@hotmail.com

fsoares@dei.uminho.pt

*Algoritmi Research Centre,University of Minho, Campus de Azurém, 4800058 Guimarães, Portugal

Vitor Carvalho*

Demétrio Matos

Orlando Lopes

vcarvalho@ipca.pt

dmatos@ipca.pt

orlandolopess@hotmail.com

Polytechnic Institute of Cávado and

Ave, School of Technology, Campus of IPCA, 4750-810 Barcelos, Portugal

José Machado

jmachado@dem.uminho.pt

MEtRICs Research Centre, Mechanical

Engineering Department. Campus of

Azurém, 4800-058 Guimarães, Portugal 